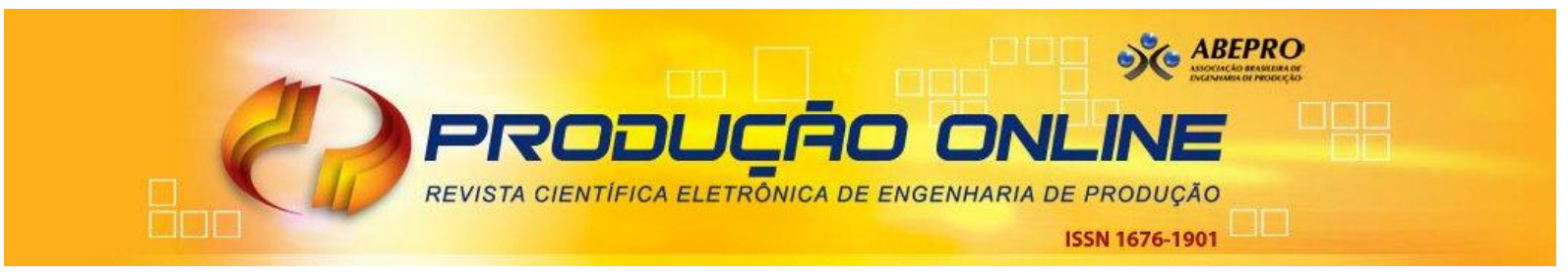

\title{
GERENCIAMENTO DE PORTFÓLIO DE PRODUTOS NA INDÚSTRIA: ESTADO DA ARTE
}

\section{PRODUCT PORTFOLIO MANAGEMENT IN INDUSTRY: STATUS QUO}

\author{
Leonardo Ensslin*E-mail: ensslin@deps.ufsc.br \\ Sandra Rolim Ensslin*E-mail: sensslin@gmail.com \\ Marcel Viana de Souza*E-mail: marcel viana@hotmail.com \\ *Universidade Federal de Santa Catarina (UFSC) Florianópolis, SC
}

\begin{abstract}
Resumo: $O$ acirramento da concorrência de produtos manufaturados tem compelido as empresas a buscarem alternativas mais criativas e inovadoras para manter-se no mercado, uma destas é a diversificação dos produtos. O presente trabalho se propõe a construir o conhecimento decorrente da evidenciação e análise dos artigos de maior reconhecimento científico para o tema Gerenciamento de Portfólio de Produtos segundo a percepção e delimitações de um pesquisador. Com tal propósito foi utilizado o processo ProKnow-C, que permitiu identificar na literatura um conjunto de 14 artigos com reconhecimento científico e com conteúdos alinhados com a visão do tema do pesquisador. Para esta amostra identificou-se os 2 periódicos com maior participação, os 4 autores de maior relevância e as 6 palavras-chave mais utilizadas. Evidenciou-se que poucos autores reconhecem o ambiente físico do contexto como único, e nenhum reconhece os limites de conhecimento do decisor. Com relação à mensuração, a maioria se vale de escalas ordinais, e poucos utilização do processo de integração dos critérios avaliados. Quase a totalidade dos artigos se vale de diagnósticos descritivos, e apenas um realiza o diagnóstico numérico. Nenhum dos estudos possuía ainda um processo estruturado para gerar ações de aperfeiçoamento.
\end{abstract}

Palavras-chave: Portfólio de Produtos. Gestão de Portfólio. Análise Bibliométrica e Análise Sistêmica.

\begin{abstract}
Increased competition for manufactured products has compelled companies to seek more creative and innovative alternative to get the market, one strategy is the diversification of products. The management of product portfolio thus assumes a new status in business terms as well as academic research. This article aims to build the knowledge arising from the disclosure of scientific articles increased recognition to the topic Portfolio Products Management and boundaries in the perception of a researcher. For this purpose we used the process ProKnow-C, which identified in the literature a set of 14 articles with scientific recognition and content aligned with the vision of the theme of the researcher. For this sample we identified the four journals with greater participation, the most prominent article, the four authors of the six most relevant and most used keywords. It was evident that few authors recognize the context of the physical environment as singular, and no recognizes limits of knowledge of the decision maker. Related to measurement, the majority relies on ordinal scales, and few use the integration process of the evaluated criteria. Almost of all articles relies on diagnostic descriptions, and only one use numerical diagnosis. None of them had a structured process for improvement actions.
\end{abstract}

Keywords: Product Portfolio. Portfolio Management. Product. Bibliometric Analysis and Systemic Review.

Revista Produção Online, Florianópolis, SC, v.14, n. 3, p. 790-821, jul./set. 2014. 


\section{INTRODUÇÃO}

A gestão de projetos tradicional concentra-se basicamente na eficiência, no desempenho operacional, no tempo e nas metas de orçamento. No entanto, hoje com um ambiente dinâmico de negócios e a competição global é necessário encontrar novas maneiras de fazer projetos que possuam poderosas armas competitivas (BROWN e EISENHARDT, 1998).

Uma ferramenta poderosa de competitividade, como apresentado por Agard e Kusiak (2004), está relacionada ao fato de que a indústria precisa possuir produtos diversificados para satisfazer as necessidades de seus clientes. Porém duas questões importantes para a realização deste objetivo devem ser levadas em conta. A primeira diz respeito à diversidade adequada para um determinado mercado, ao passo que a segunda se refere à gestão e fabricação de produtos dentro de um tempo de espera razoável e com um custo aceitável (FONSECA e ROZENFELD, 2012).

Tseng e Jiao (1999) sugerem que a variedade funcional (relacionadas à satisfação do consumidor) deve ser promovida na fase de desenvolvimento, e as variáveis técnicas, relacionados com a complexidade de fabricação e custo de produção devem ser reduzidas.

Ao invés de oferecer ao mercado produtos genéricos, que correspondem a uma média da satisfação das necessidades de vários clientes, as empresas estão perseguindo uma estratégia de customização, que se esforça para oferecer produtos com foco no cliente, com um elevado grau de individualidade. Porém, ao mesmo tempo que uma estratégia de alta variedade pode oferecer um meio eficaz para empresas se diferenciarem de seus concorrentes, inevitavelmente, oferecerá também uma alta complexidade.

A grande variedade de produtos pode causar certo desconforto ao cliente pela grande complexidade envolvida ao fazer uma escolha. Portanto, torna-se imperativo para as empresas determinar a oferta correta da variedade de produtos para 0 mercado-alvo (JIAO et al., 2004). 
Sendo assim, a necessidade de estabelecer um modelo de avaliação de desempenho de portfólio de produtos requer a construção de um referencial teórico que reflita os mais relevantes e atualizados conhecimentos acadêmicos neste campo. Portanto, o processo de procura deve partir do pressuposto de que o conhecimento acadêmico é amplamente disperso em uma variedade de publicações, bancos de dados e outras fontes de pesquisa. Este conhecimento amplamente difundido, em última instância deve ser coletado em um processo estruturado para a seleção de estudos com de alta relevância acadêmica sobre o contexto do estudo, a fim de fornecer um sólido quadro teórico (AZEVEDO et al. (2011); BORTOLUZZI et al. (2011); BRUNA JUNIOR et al. (2012); ENSSLIN e VIANNA (2008); LACERDA et al. (2011); LACERDA, et al. (2012); ROSA et al. (2012); ROSA et al. (2011); TASCA, et al. (2010); VEGINI et al. (2012).

Com isso, chega-se ao ponto crucial da pesquisa: Como construir no pesquisador o conhecimento que lhe permita identificar um portfólio bibliográfico composto pelos artigos de maior reconhecimento científico e ao mesmo tempo alinhados com a percepção do tema e delimitações do pesquisador, e para esta amostra evidenciar os mais destacados artigos, autores, periódicos e palavras-chave.

O objetivo global desta pesquisa é construir o conhecimento inicial demandado por um pesquisador para o tema gestão de portfólio de produtos sob a ótica de seus resultados para seu gestor.

Para alcançar objetivo global foram propostos os seguintes objetivos específicos:

(i) Selecionar um referencial teórico sobre gestão de portfólio de produtos sob a ótica de seus resultados para seu gestor; e

(ii) Evidenciar os artigos, os autores, periódicos e palavras-chave de maior relevância, no referencial teórico selecionado.

(iii) Analisar este portfólio de artigos segundo as lentes conceito, singularidade, reconhecer os limites de conhecimento, mensuração, integração e gestão.

Para atingir esses objetivos, este estudo adotou o processo denominado ProKnow-C (Knowledge Development Process - Constructivist) (ENSSLIN et al., 2010a), que se inicia pelo interesse do pesquisador sobre um determinado tema, bem 
como suas delimitações e restrições intrínsecas ao contexto acadêmico, em busca da construção do conhecimento no pesquisador, a fim de que ele possa iniciar uma pesquisa científica com fundamentação. A construção desse conhecimento no pesquisador é aqui representada pela seleção dos artigos relevantes que comporão o portfólio bibliográfico relacionado ao tema de avaliação de desempenho na gestão estratégica, bem como a análise bibliométrica e sistêmica desses artigos. O conceito de análise bibliométrica se baseia na evidenciação quantitativa dos parâmetros de um conjunto definido de artigos (portfólio bibliográfico) para a gestão da informação e do conhecimento científico de um dado assunto. Os parâmetros observáveis são: os artigos selecionados, suas referências, autores, número de citações e periódicos mais relevantes (ENSSLIN et al., 2010a). A análise sistêmica é um processo científico utilizado para, a partir de uma visão de mundo (filiação teórica) definida e explicitada por suas lentes, analisar uma amostra de artigos representativa de um dado assunto de pesquisa, visando evidenciar para cada lente e globalmente, para a perspectiva estabelecida, os destaques e as oportunidades (carências) de conhecimentos encontrados na amostra (ENSSLIN et al., 2010a).

Este artigo se divide em quatro seções, além dessa introdução. Na segunda seção se encontra o enquadramento metodológico da presente pesquisa. Na seção seguinte, é apresentado o processo de seleção dos artigos, a análise bibliométrica e a análise sistêmica. Na quarta seção apresentam-se as conclusões. Por fim, é apresentada a seção das referências bibliográficas utilizadas ao longo do texto.

\section{METODOLOGIA}

Um quadro metodológico consiste em um exame, descrição ou explicação das abordagens e ferramentas utilizadas na pesquisa, a fim de especificar o conjunto de métodos, procedimentos e pressupostos filosóficos que fundamentam o tema. A falta de um padrão estabelecido que permita a adoção de um procedimento único no que diz respeito à metodologia de pesquisa faz com que a escolha do quadro metodológico se modifique de acordo com as percepções do pesquisador e os objetivos da pesquisa (PETRI, 2005).

Revista Produção Online, Florianópolis, SC, v.14, n. 3, p. 790-821, jul./set. 2014. 
Quanto aos objetivos, pode ser descrita como pesquisa exploratória, o que segundo Gil (2002) objetiva proporcionar maior familiaridade com o problema, para torná-lo mais explícito.

Esta pesquisa também se caracteriza como quali-quantitativa. A dimensão qualitativa tem o objetivo de aprofundar o conhecimento sobre o fenômeno, por meio da identificação dos critérios e a construção de escalas em um primeiro momento ordinais que irão compor o modelo ordinal de avaliação. Já a quantitativa, faz uso de modelos matemáticos para converter as escalas ordinais em escalas cardinais e, posteriormente, para identificar taxas de substituição que servirão para integrar os critérios do modelo e permitir uma avaliação de desempenho global (ENSSLIN e VIANNA, 2008). Segundo Ensslin (2002), as pesquisas qualitativas e quantitativas coexistem nos modelos construtivistas como da MCDA-C, uma vez que todo conhecimento é inicialmente qualitativo requerendo sua quantificação, num segundo momento, para agregar conhecimento preferencial quanto à diferença de atratividade entre os níveis inicialmente ordinais (ENSSLIN et al., 2010; TASCA et al., 2010).

\section{PROCESSO DE INTERVENÇÃO}

Essa seção apresenta os procedimentos utilizados para a seleção dos artigos que comporão o portfólio de artigos da presente pesquisa e que serão utilizados para a análise bibliométrica, que consistirá em identificar os periódicos com maior participação, os autores de maior relevância e as palavras-chave mais utilizadas, e a análise sistêmica, visando evidenciar para cada lente, a perspectiva estabelecida, os destaques e as oportunidades de conhecimentos encontrados na amostra.

O instrumento de intervenção utilizado é o processo para construir conhecimento a partir dos interesses e delimitações de pesquisadores, segundo a visão construtivista, Knowledge Development Process-Constructivist (ProKnow-C), demonstrado nos trabalhos de Ensslin et al. (2012); Bruna Junior et al. (2012); Afonso et al. (2012); Chaves et al. (2012a), Back et al. (2012), Bortoluzzi et al. (2011), Lacerda et al. (2012); Marafon et al. (2012) e Chaves et al. (2012b). 
Para iniciar a pesquisa algumas restrições foram estabelecidas:

- Tipo de documento pesquisa: Somente artigos, pois passaram por um crivo técnico;

- Data de Publicação: Documento publicados entre Jan/2001 e Jan/2011;

- Base de dados consultadas: Emerald, Oxford, HighWire, Scopus, Web of Science, Compendex, Wilson, Wiley e Science Direct; Todas indexadas pela CAPES e com enquadramento teórico com o eixo de pesquisa.

- Palavras-chave: Para definir as palavras chaves foram inicialmente estabelecidos os eixos de pesquisa e a partir destes estabeleceu-se as combinações que os contemplassem. Os eixos foram definidos como: gestão de portfólio de produtos sob a ótica de seus resultados para seu gestor; e (ii) avaliação de desempenho. O primeiro representa o tema central da pesquisa e o segundo trata do desempenho ou performance do portfólio de produtos, sendo recomendada uma visão de avaliação de desempenho para analisá-la. (ENSSLIN, et al, 2010).

Associou-se as palavras-chaves do eixo de avaliação de desempenho (performance evaluation, performance appraisal, performance assessment, performance measurement), com as palavras relacionadas ao eixo de pesquisa (product portfolio, portfolio analysis, portfolio strategy, portfolio management), formando um conjunto de 16 palavras compostas.

\subsection{Processo de Seleção de Artigos}

Após definição das restrições inicia-se o processo de seleção dos artigos que comporão o portfólio de artigos com maior relevância sobre o tema em estudo. Utilizando das palavras-chave anteriormente definidas e a data de publicação, as buscas nas bases de dados retornaram um portfólio total bruto de 5936 artigos.

Utilizou-se como ferramenta de gerenciamento de referências o software Endnote (THE THOMSON, 2008).

Seguindo o processo Proknow-C, na etapa de filtro do Banco de Artigos Bruto (BAB) quanto a redundância, foi importado o portfólio total bruto de 5936 artigos para o Revista Produção Online, Florianópolis, SC, v.14, n. 3, p. 790-821, jul./set. 2014. 
EndNote, e excluindo os artigos duplicados, chegando-se a um total de 2335 artigos não repetidos (vide Figura 1).

Figura 1 - Filtro quanto a Redundância.



Fonte: Adaptado de ProKnow-C (Knowledge Development Process-Constructivist), 2010.

Uma vez excluídos os duplicados, na etapa de filtro do BAB não repetidos quanto ao alinhamento do título, segundo o Proknow-C, passou-se a leitura dos títulos dos artigos para observar o alinhamento desses com a presente pesquisa. Após essa análise, obteve-se um total de 530 artigos alinhados com o tema de pesquisa (vide Figura 2).

Revista Produção Online, Florianópolis, SC, v.14, n. 3, p. 790-821, jul./set. 2014. 
Figura 2 - Filtro quanto Alinhamento do Título

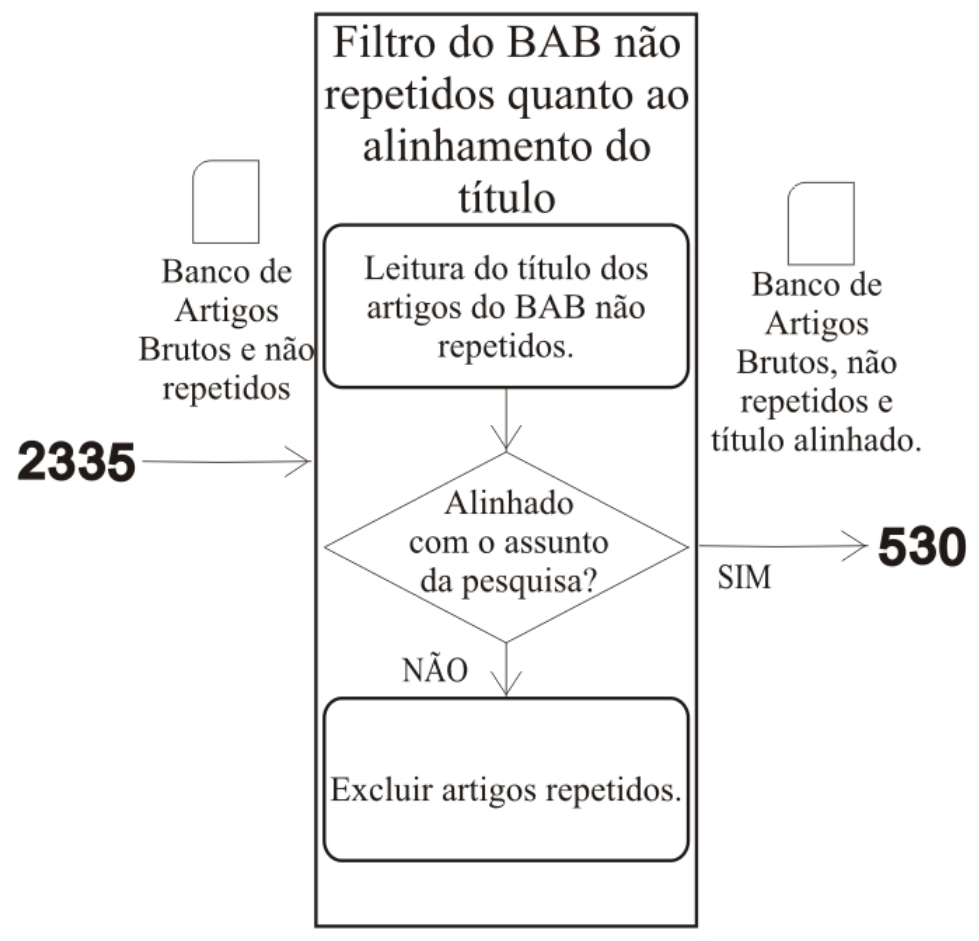

Fonte: Autores

Utilizou-se o número de citações no meio acadêmico para analisar o reconhecimento científico dos 530 artigos que possuíam título alinhado. Para realizar essa análise, foram consultadas na ferramenta de pesquisa Google Scholar (em Jan/2011) o número de citações de cada um dos 530 artigos do Portfólio Bibliográfico e ordenadas de forma decrescente.

Utilizando a regra de Pareto, os autores da presente pesquisa estabeleceram um valor de corte, onde $23,8 \%$ dos artigos mais citados correspondem a $80 \%$ de todas as citações obtidas pelos 530 artigos alinhados pelo título.

Sendo assim, 127 artigos foram selecionados como sendo alinhados pelo título e com reconhecimento científico, conforme se pode observar nas Figuras 3 e 4. 
Figura 3- evidenciação do valor de corte conforme suas citações

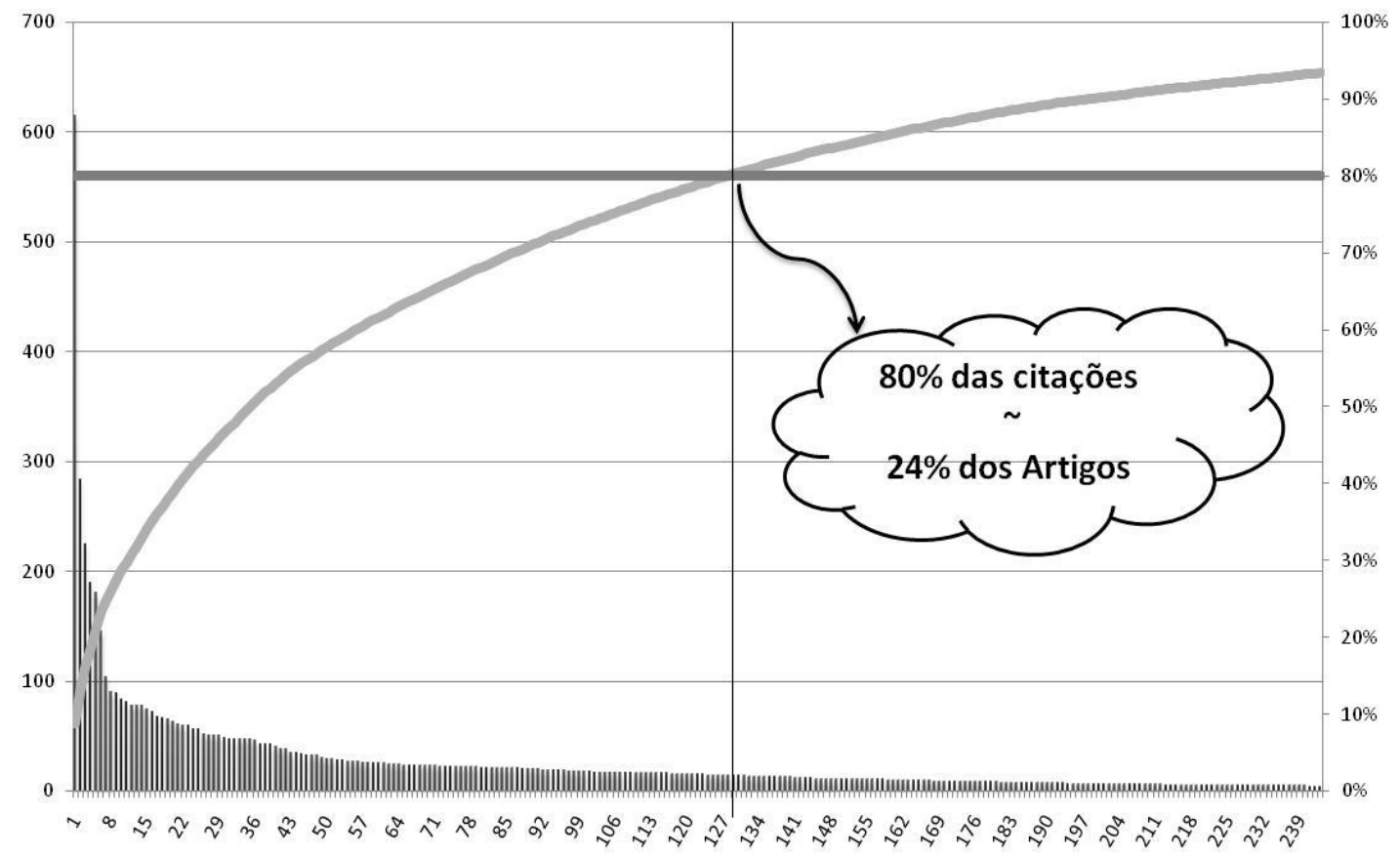

Fonte: Autores

Figura 4 - fragmento do processo quanto ao reconhecimento científico

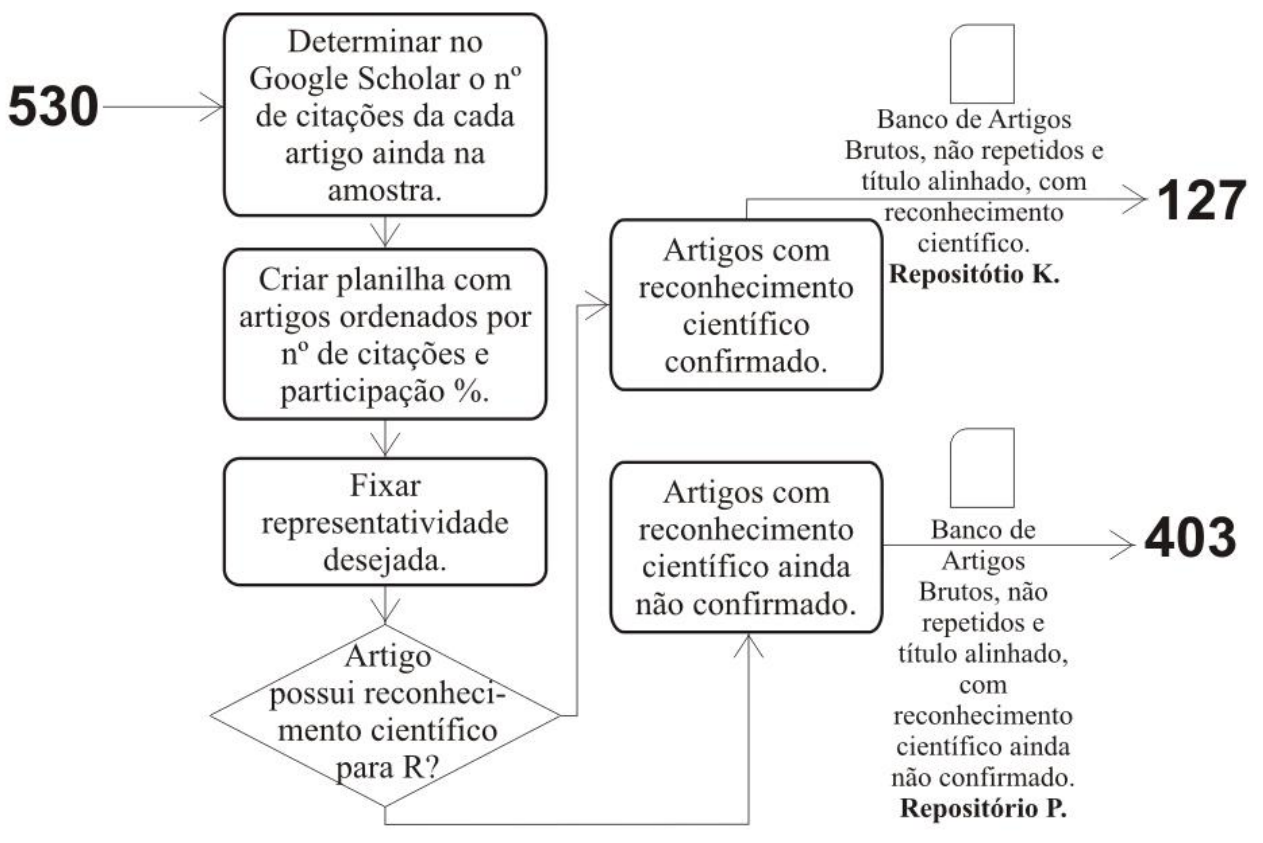

Fonte: Autores

Revista Produção Online, Florianópolis, SC, v.14, n. 3, p. 790-821, jul./set. 2014. 
Vale ressaltar que os 403 artigos menos citados ainda passarão por um processo de análise sob outros critérios, pelos quais poderão ainda fazer parte do portfólio bibliográfico de artigos que farão parte do referencial teórico da pesquisa.

Uma vez selecionados os artigos com maior reconhecimento científico, os mesmos foram analisados quanto ao alinhamento do seu resumo (abstract) ao tema de pesquisa em questão.

Dos 127 resumos analisados, 12 foram selecionados como alinhados pelo resumo com o tema de pesquisa.

Dessa forma, conforme explicitados na Figura 5 restaram 12 artigos que:

1. Estão alinhados frente à leitura de título e resumo;

2. Possuem reconhecimento científico;

Figura 5 - fragmento do processo quanto ao reconhecimento científico.

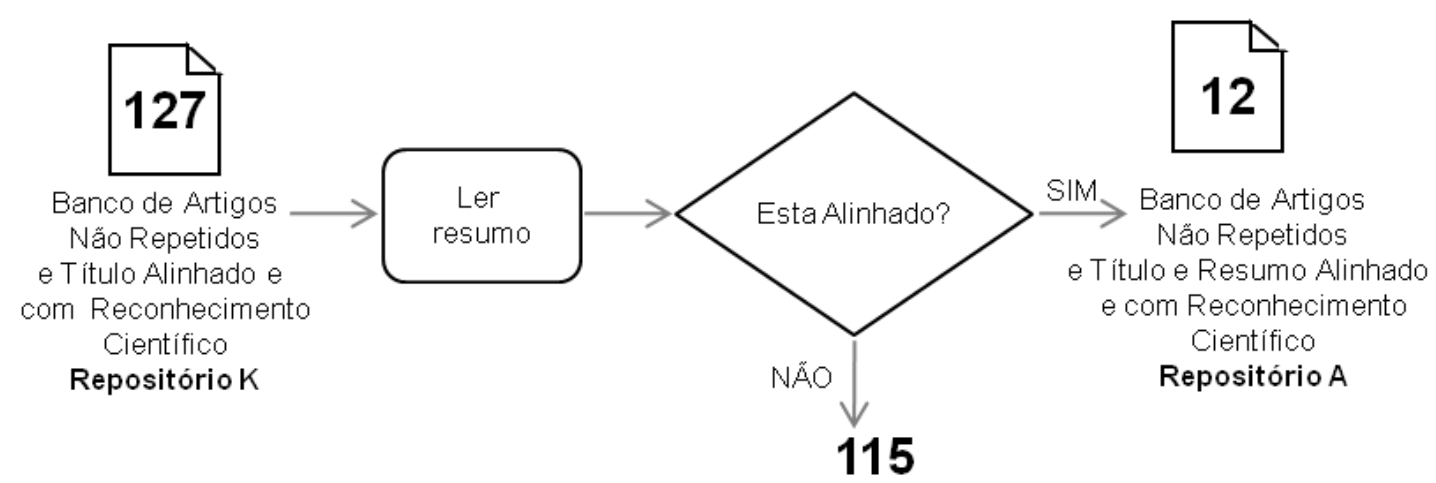

Fonte: Autores

Para que algum artigo com menor número de citações seja selecionado no portfólio bibliográfico da pesquisa, o processo definiu duas condições possíveis:

i. Artigos publicados a menos de 2 anos da análise, considerando que não tiveram possibilidades de serem bem citados ainda e;

ii. Se os artigos publicados a mais de 2 anos são de autoria de algum pesquisador já presente no grupo dos 12 artigos alinhados quanto ao resumo e com relevância científica.

Revista Produção Online, Florianópolis, SC, v.14, n. 3, p. 790-821, jul./set. 2014. 
Com essas duas condições, dos 403 artigos com poucas citações, 146 artigos foram publicados em 2011, 2010 ou 2009.

Dos 257 artigos que foram publicados anteriormente ao ano de 2009, apenas 3 artigos são de autores presentes no portfólio dos artigos já selecionados.

Assim, dos 149 artigos selecionados para o processo de re-análise, 3 artigos foram selecionados após leitura de seus resumos.

A Figura 6 ilustra o processo de re-análise e explicita a quantidade de artigos que passaram em cada atividade do processo de seleção de artigos.

Figura 6 - Fragmento do processo, foco na re-análise de artigos menos citados

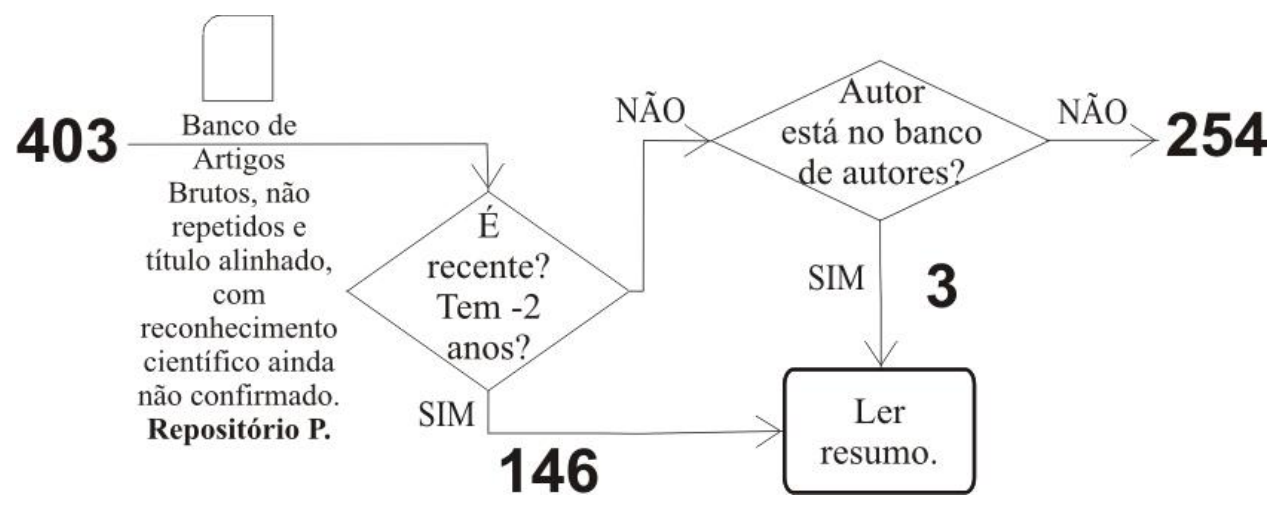

Fonte: Autores

Assim, ao final deste processo, obteve-se o total de 14 artigos com reconhecimento científico, alinhados com o tema de pesquisa, que foram selecionados para compor o portfólio bibliográfico sobre Avaliação de Desempenho de Portfólio de Produtos.

A Figura 7 explicita graficamente, seguindo as etapas do Proknow-C, os procedimentos e os quantitativos das atividades finais para a composição do portfólio bibliográfico com 14 artigos, nomeados por ordem alfabética do primeiro autor: Agard, e Kusiak (2004); Cooper et al. (2001); David et al. (2002); Ernst, H. (2002); Hart et al. (2003); Jiao e Zhang (2005); Krishnan e Ulrich (2001); Minarro-Viseras, et al. (2005); Morgan e Rego (2009); Ramdas et al. (2003), Shenhar (2004); Sheu et al. (2003); Tatikonda e Montoya-Weiss (2001); Yu e Wang (2010). 
Figura 7 - Fragmento final do processo para seleção de artigos



Fonte: Autores

\subsection{Análise Bibliométrica}

A análise bibliométrica do portfólio bibliográfico para o desenvolvimento do referencial teórico sobre avaliação de desempenho de portfólio de produtos, foi dividido em 2 etapas:

i. Análise bibliométrica dos artigos selecionados;

ii. Análise bibliométrica das referências dos artigos selecionados;

\subsubsection{Análise bibliométrica dos artigos selecionados}

$\mathrm{Da}$ análise bibliométrica dos artigos selecionados, resultaram em 2 aspectos avaliados:

i. Reconhecimento científico pelo número de citações, conforme Figura 8;

ii. Número de artigos por periódico, conforme Figura 9;

Revista Produção Online, Florianópolis, SC, v.14, n. 3, p. 790-821, jul./set. 2014. 
Figura 8 - Número de citações dos artigos do portfólio

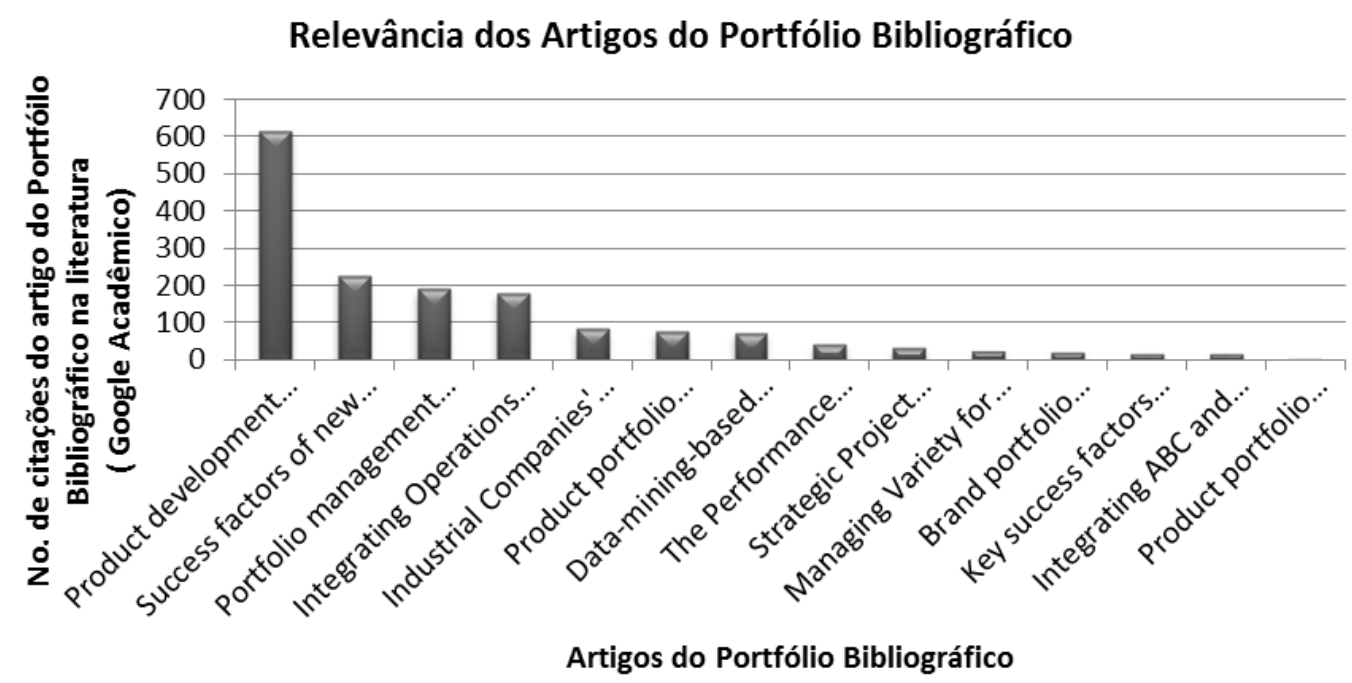

Fonte: Autores

Destaca-se o trabalho de Krishnan e Ulrich (2001) com 615 citações desde sua publicação até janeiro de 2011.

Figura 9 - Número de artigos por periódicos.

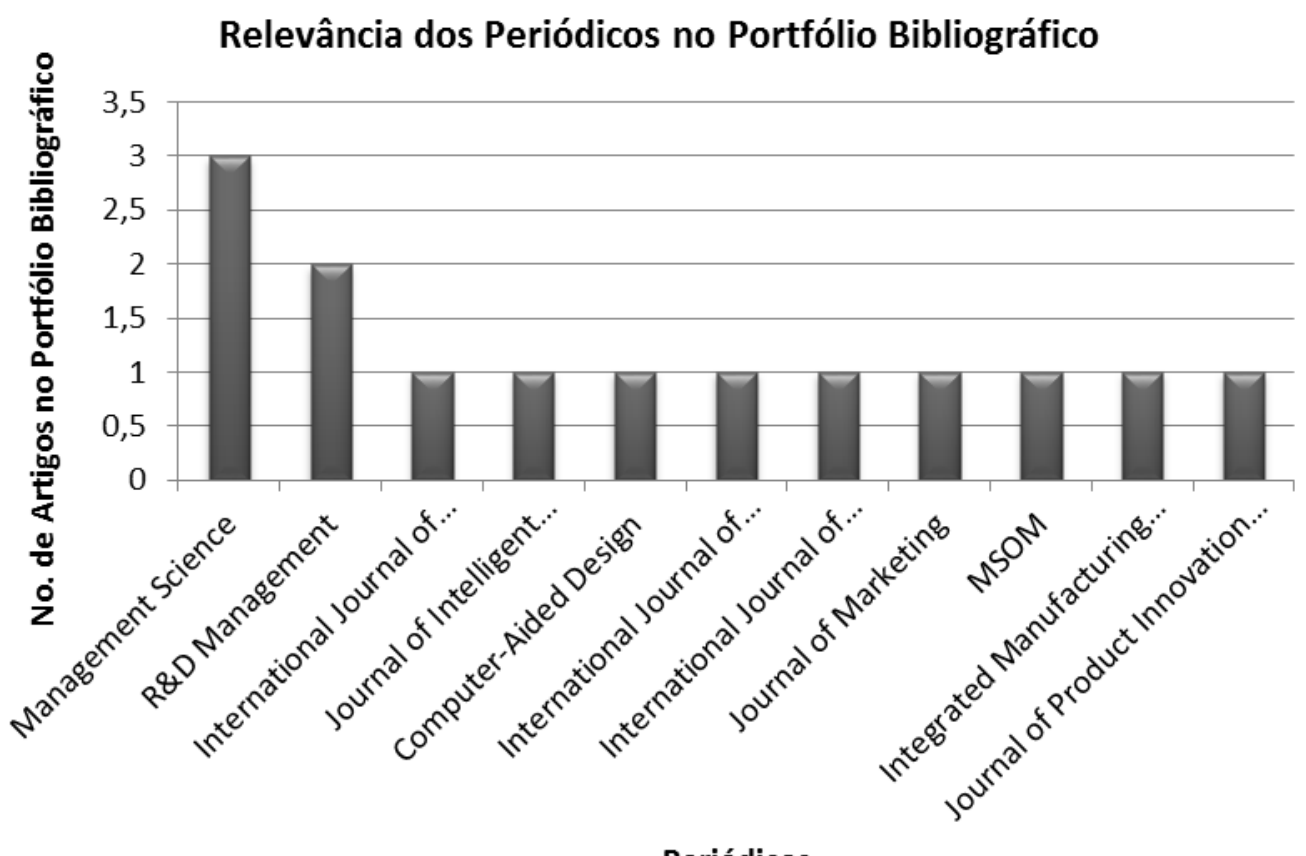

Fonte: Autores

Revista Produção Online, Florianópolis, SC, v.14, n. 3, p. 790-821, jul./set. 2014. 
O Periódico Management Science possui 3 artigos do portfólio bibliográfico sobre avaliação de desempenho de portfólio de produtos.

\subsubsection{Análise bibliométrica das referências dos artigos selecionados}

Com vistas a identificar os autores que se destacam no tema de pesquisa, foram agrupadas todas as referências citadas pelos 14 artigos que compõem o portfólio bibliográfico, conforme figura 10.

Figura 10 - Número de publicações dos Autores nas referências

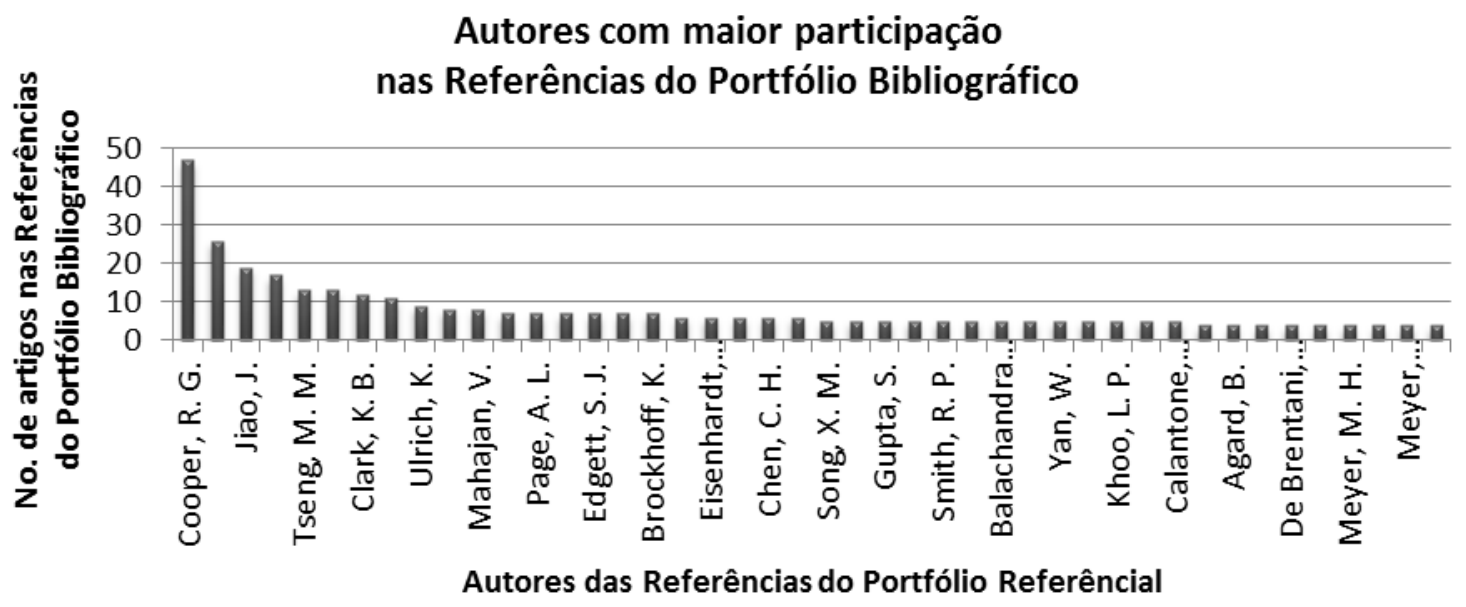

Fonte: Autores

Destaca-se o autor Robert Cooper com 47 artigos publicados nas referências do portfólio bibliográfico neste estudo.

Uma vez definido o portfólio do referencial teórico e realizada a análise bibliométrica, desenvolveu-se a etapa de Análise Sistêmica, como será apresentado na seção seguinte.

Revista Produção Online, Florianópolis, SC, v.14, n. 3, p. 790-821, jul./set. 2014. 


\subsection{Análise Sistêmica}

A análise sistêmica é um processo científico utilizado para, a partir de uma visão de mundo (filiação teórica) definida e explicitada por suas lentes, analisar uma amostra de artigos representativa de um dado assunto de pesquisa, visando evidenciar para cada lente e, globalmente, para a perspectiva estabelecida, os destaques e as oportunidades (carências) de conhecimentos encontrados na amostra. (ENSSLIN et al., 2010).

A análise sistêmica do portfólio dos 14 artigos selecionados inicia-se pela identificação dos pontos de vistas pelos quais os pesquisadores irão analisar o conteúdo dos artigos. Tais pontos de vistas foram derivados do conceito de avaliação de desempenho adotado pela presente pesquisa:

Avaliação de Desempenho é o processo para construir conhecimento no decisor, a respeito do contexto específico que se propõe avaliar, a partir da percepção do próprio decisor por meio de atividades que identificam, organizam, mensuram ordinalmente e cardinalmente, e sua integração e os meios para visualizar o impacto das ações e seu gerenciamento. (ENSSLIN et al., 2010)

A partir deste conceito, este artigo estruturou as lentes de Brunswik (STEWART, 2001), pelas quais a análise sistêmica dessa pesquisa foi realizada, apresentadas no quadro 1 (ENSSLIN et al., 2010).

Revista Produção Online, Florianópolis, SC, v.14, n. 3, p. 790-821, jul./set. 2014. 
Quadro 1 - Lentes da Avaliação de Desempenho do LabMCDA

\begin{tabular}{|c|c|c|}
\hline ID & LENTE & O QUE BUSCA? \\
\hline 1 & CONCEITO & Qual a filiação teórica? \\
\hline 2 & SINGULARIDADE & Reconhece que o problema é único? \\
\hline 3 & $\begin{array}{c}\text { PROCESSO PARA } \\
\text { IDENTIFICAR }\end{array}$ & $\begin{array}{c}\text { Tem processo para identificar os objetivos segundo } \\
\text { a percepção do decisor? }\end{array}$ \\
\hline 4 & MENSURAÇÃO & Reconhece que os descritores são escalas ordinais? \\
\hline 5 & INTEGRAÇÃO & Reconhece que a integração requer níveis de \\
\hline 6 & GESTÃO & $\begin{array}{c}\text { O conhecimento gerado permite conhecer o perfil } \\
\text { atual, sua monitoração e aperfeiçoamento? }\end{array}$ \\
\hline
\end{tabular}

Fonte: (ENSSLIN et al., 2010)

$\mathrm{Na}$ literatura é vasto o universo de publicações em torno da definição e objetivo da Revisão Sistêmica. Para efeito deste trabalho será adotada a definição proposta por Ensslin et. al. (2010) "Processo científico utilizado para, a partir de uma visão de mundo (filiação teórica) definida e explicitada por suas lentes, analisar o Portfólio Bibliográfico para o tema de pesquisa Gestão de Portfólio de Produtos, visando evidenciar para cada lente e globalmente, os destaques e as oportunidades de pesquisa sobre o tema em estudo".

Uma vez definidas as lentes de pesquisa, a seção seguinte apresentará os resultados da revisão sistêmica da literatura para cada lente.

\subsubsection{Resultados da revisão sistêmica da literatura}

Definidas as lentes de pesquisa, as seções seguintes relatam os resultados da análise de conteúdo dos artigos selecionados, tendo como norte as lentes derivadas da visão de mundo adotada na avaliação de desempenho. 


\subsubsection{1 lente 1: conceito}

O conceito de Avaliação de Desempenho buscou identificar a afiliação teórica ao qual pertence o método utilizado, conforme ilustrado na Figura 11.

Figura 11 - Lente 2: Singularidade

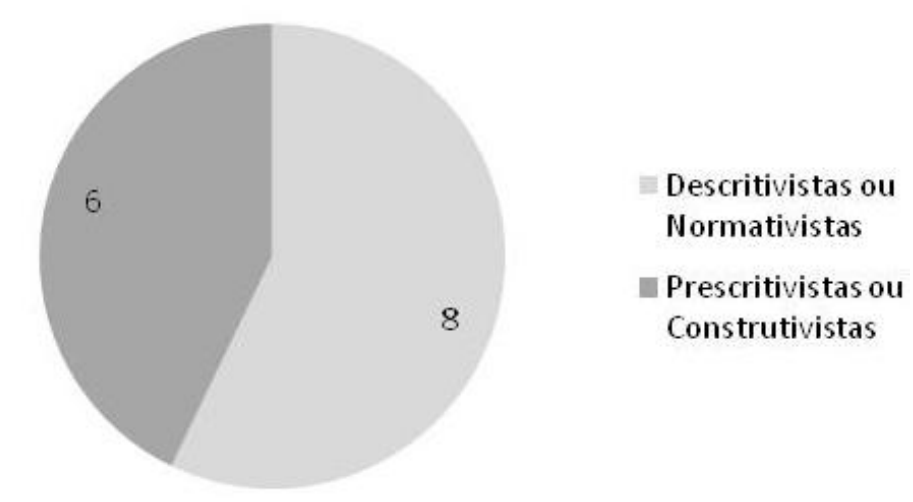

Fonte: Autores

A análise sistêmica evidenciou que a maioria dos autores foca o processo de "Gestão de Portfólio de Produtos" em alternativas sem um reconhecimento das vantagens do todo. Emerge assim nesta lente a oportunidade de contribuir com propostas holísticas para avaliar a "Gestão de Portfólio de Produtos, sob o enfoque de resultados segundo a percepção de seu gestor".

\subsubsection{2 lente 2: singularidade}

A avaliação de desempenho é realizada pela identificação e mensuração de propriedades físicas do contexto que estão associadas aos valores daquele que avalia, o gestor. Esta situação faz com que a avaliação fundamentada seja aquela que é construída e utilizada apenas para o contexto onde foi desenvolvida e é realizada segundo os valores e preferências do gestor. (ROY, 1993; ENSSLIN et al., 2010).

Revista Produção Online, Florianópolis, SC, v.14, n. 3, p. 790-821, jul./set. 2014. 
Segundo LACERDA, et al. (2011a) esse reconhecimento da singularidade garante que o conjunto de instrumentos de apoio ao processo decisório seja reconhecido pelo decisor como representativo de seus valores e preferências. Isto cria alinhamento, coerência, rapidez e assertividade nas decisões. Por sua vez, a organização passa a alcançar seus objetivos, uma vez que estes estão embutidos nos critérios do decisor. Quando, no entanto, os critérios forem os de mercado, estes explorarão valores que na maioria das vezes não são almejados pelo decisor e pela organização, desperdiçando esforços e reduzindo o alcance dos reais objetivos.

Da mesma forma, evidencia Skinner (1986), que promover a Avaliação de Desempenho de forma genérica (indicadores padrão) é o erro mais comum nas diferentes empresas pesquisadas por ele. O diferencial competitivo das empresas, públicas e privadas, deve-se a utilização de estratégias individuais e personalizadas ao contexto.

Sendo assim, os artigos foram analisados de forma a avaliar se os autores desenvolviam seus modelos em um contexto físico e depois restringiam seu uso ao mesmo e a participação do decisor. Com tais propósitos buscou-se, nesta lente, resposta nos artigos do Portfólio Bibliográfico para as seguintes questões:

a) Atores:

i. Número de artigos que reconhecem e identificam o decisor;

ii. Número de artigos que não reconhecem e nem identificam o decisor;

b) Ambiente

i. Número de artigos em que o autor desenvolve o modelo para uma organização e reconhece e pratica que o modelo somente pode ser aplicado para esta organização;

ii. Número de artigos em que o autor não reconhece e nem pratica que o ambiente físico do contexto é único;

Desta forma, no âmbito dos Atores a Figura 12 ilustra os resultados alcançados, evidenciando que os trabalhos de Krishnan e Ulrich (2001) e Hart, et al. (2003) não reconhecem nem identificam o decisor.

Revista Produção Online, Florianópolis, SC, v.14, n. 3, p. 790-821, jul./set. 2014. 
Figura 12 - Lente 2: Singularidade - Atores.

\section{Atores}

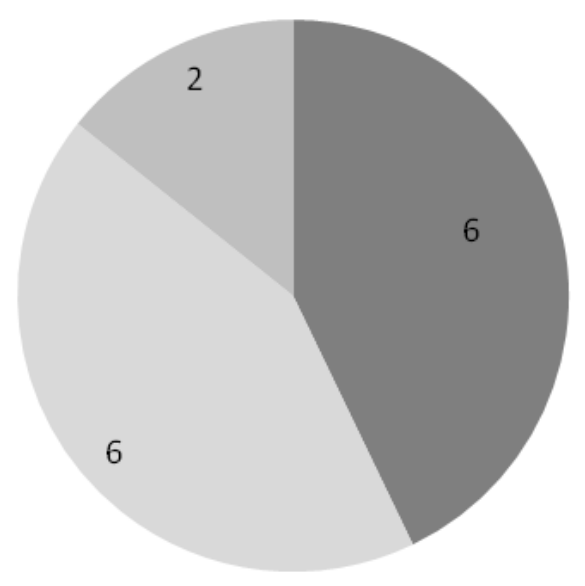

Reconhecem e identificam o decisor;

Identificam o decisor no trabalho, mas não o tem em conta para a construção integral do modelo.

Não identificam o decisor no trabalho.

Fonte: Autores

Figura 13 - Lente 2: Singularidade - Ambiente

\section{Ambiente}

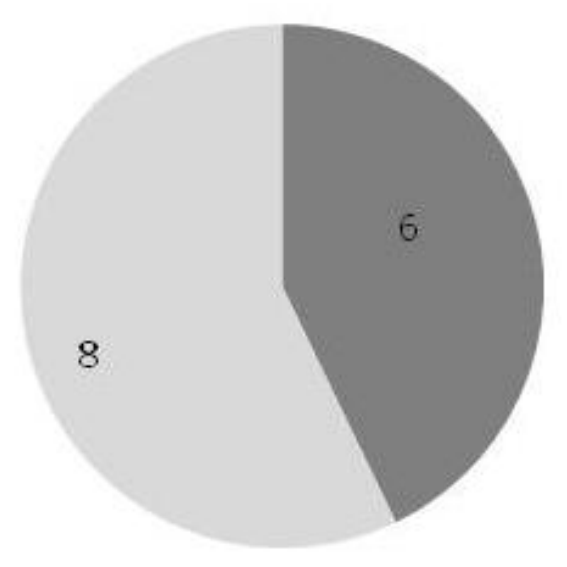

Número de artigos que desenvolve o modelo para um contexto físico e reconhece que o modelo é valido somente para este contexto físico.

Não reconhece 0 ambiente físico do contexto como único

Fonte: Autores

Revista Produção Online, Florianópolis, SC, v.14, n. 3, p. 790-821, jul./set. 2014. 
A Figura 13 ilustra que dos 14 artigos do portfólio bibliográfico, o reconhecimento do ambiente físico do contexto como único é observado nos seis trabalhos: Agard e Kusiak (2004), Krishnan e Ulrich (2001); Jiao, et al.. (2004); Cooper, et al,. (2001); Tatikonda, et al,. (2001) e Ramdas, K., et al. (2003).

\subsubsection{3 lente 3: reconhece os limites do conhecimento do decisor}

A terceira lente busca compreender o processo apresentado pelo autor no artigo do portfólio bibliográfico com relação ao reconhecimento dos limites do conhecimento do decisor. Esta lente é subdividida em duas etapas:

a) Geração do Conhecimento

i. Número de artigos que não levam em conta a necessidade de expansão do conhecimento do decisor;

ii. Número de artigos que levam em conta a necessidade de expansão do conhecimento do decisor somente na operacionalização dos critérios, ou os decisores adicionam novos critérios

iii. Número de artigos que levam em conta a necessidade de expansão do conhecimento do decisor na identificação e na operacionalização dos critérios;

b) Identificação dos critérios

i. Número de artigos onde a identificação é externa;

ii. Número de artigos onde os critérios são identificados externos, mas a operacionalização é segundo os valores do decisor;

iii. Número de artigos onde os critérios e sua a operacionalização são segundo os valores do decisor;

As Figura 14 e 15 evidenciam os resultados da análise com relação a lente 3 no contexto do reconhecimento dos limites do entendimento do decisor. 
Figura 14 - Lente 3.1: Geração do conhecimento

\section{Geração do conhecimento}

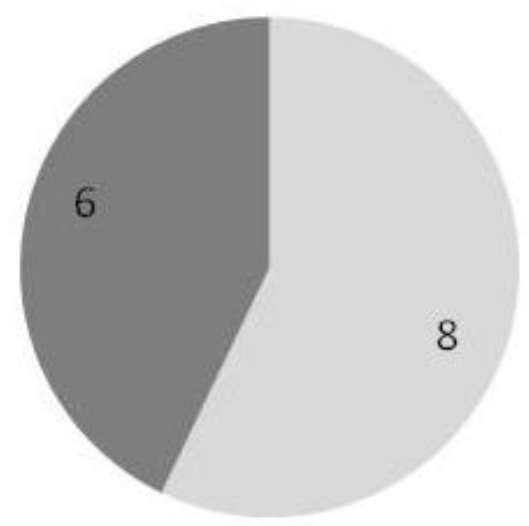

Não levam a expansão do conhecimento;

- Operacionalização dos critérios, mas não em sua identificação;

Fonte: Autores

Figura 15 - Lente 3.2: Processo para Identificar

\section{Identificação dos critérios}

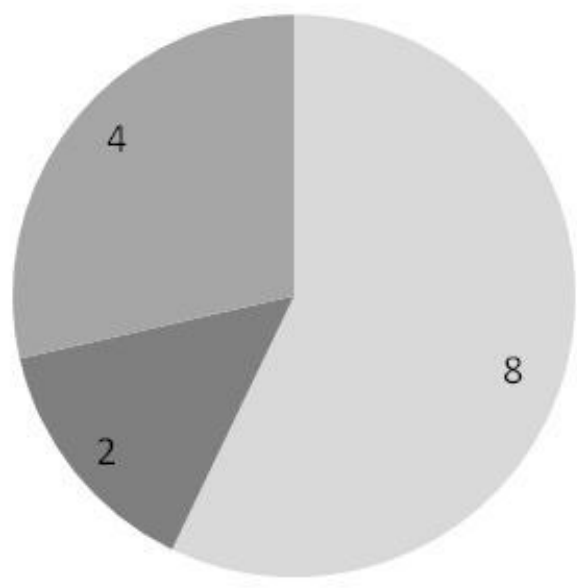

Segundo os valores do decisor;

- Parcialmente alicerçado nos valores do decisor;

- NÃO tem em conta osvalores do decisor.

Fonte: Autores

Revista Produção Online, Florianópolis, SC, v.14, n. 3, p. 790-821, jul./set. 2014. 
Os seis artigos que realizam a Gestão de Portfólio de Produtos no âmbito de reconhecer os limites de conhecimento com a operacionalização dos critérios, mas não em sua identificação, destacam-se: Agard, B., et al. (2004); Yu e Wang (2010); Jiao, et al. (2004); Cooper et al. (2001); Tatikonda, et al. (2001) e Ramdas et al. (2003).

Entre os 14 artigos do portfólio bibliográfico, quatro artigos no âmbito dos autores não utilizam-se de critérios e operacionalização da avaliação com a participação dos decisores: Agard e Kusiak (2004); Yu e Wang (2010); Jiao, et al. (2004) e Ramdas et al. (2003).

\subsubsection{4 lente 4: mensuração}

A mensuração tem por objetivo avaliar a construção dos indicadores de desempenho, dividindo esta lente em dois eixos:

a) Como constrói os indicadores de desempenho?

Atende teoria da mensuração: Reconhece o tipo de escala que usa? (Nominais, ordinais e cardinais). As operações realizadas estão de acordo com as estatísticas permitidas por essa escala.

Número de artigos que explicitam o tipo de escala que utiliza:

i. Número de artigos que explicitam as escalas que utiliza e não atendem suas propriedades estatísticas;

ii. Número de artigos que explicitam as escalas atendendo suas propriedades estatísticas;

iii. Número de artigos que não explicitam o tipo de escala que utiliza;

b) Atende as propriedades da operacionalização?

Esta seção analisa se os artigos que realizam a mensuração respeitam as seguintes propriedades: mensurabilidade, inteligibilidade/não-ambiguidade, homogeneidade, operacionalidade, se permite distinguir o melhor do pior e se respeita as propriedades das escalas ordinais.

i. Número de artigos em que as escalas utilizadas atendem a todas as propriedades da teoria da mensuração.

Revista Produção Online, Florianópolis, SC, v.14, n. 3, p. 790-821, jul./set. 2014. 
ii. Número de artigos em que as escalas não atendem as propriedades da teoria da mensuração.

A Figura 16 evidencia os resultados da análise com relação a lente 4 Mensuração.

Figura 16 - Lente 4.1 - Como constrói os indicadores de desempenho

\section{Como constrói os indicadores}



Explicitam as escalas atendendo suas propriedades estatísticas;

Não explicitam o tipo de escala que utiliza;

Fonte: Autores

Merece destaque os nove trabalhos que se utilizam de escalas ordinais: Agard et al. (2004); Yu e Wang (2010); Tatikonda et al.(2001); MinarroViseras et al. (2005); Morgan, et al. (2009); David et al. (2002); Ramdas et al. (2003); Jiao et al. (2005) e Hart et al. (2003). Os cinco demais não realizam mensuração. Não se identificou nenhum trabalho que explique as escalas que utiliza e não atenda suas propriedades estatísticas.

Com relação ao segundo eixo da Lente 4.2 - Atender as propriedades da operacionalização, todos os trabalhos que se propõem a realizar a mensuração dos critérios se valem de escalas ordinais tipo Likert, a qual se evidencia neste trabalho as limitações destas escalas quanto às propriedades de sua operacionalização. 


\subsubsection{5 lente 5: integração}

A integração é definida como o processo para determinação do desempenho global através da determinação de taxas de compensação para cada critério da avaliação. Esta lente foi subdividida em dois critérios:

a) Número de artigos que não realizam integração;

b) Número de artigos que realizam integração;

i. Número de artigos que realizam integração descritivamente e/ou graficamente;

ii. Número de artigos que realizam integração cardinalmente;

c) Número de artigos que utiliza níveis de referência;

d) Número de artigos que não utiliza níveis de referência;

Através da análise sistêmica para lente de Integração evidenciou-se que nenhum artigo do portfólio bibliográfico realiza o processo de integração.

\subsubsection{6 lente 6: gestão}

A última lente analisa se o conhecimento gerado permite conhecer o perfil atual, sua monitoração e aperfeiçoamento. Deste modo, a análise foi separada em dois eixos:

a) Permite diagnosticar (conhecer os pontos fortes e fracos) da situação atual

b) Número de artigos que não fazem diagnóstico;

c) Número de artigos que fazem diagnóstico;

c.1. Número de artigos que fazem diagnóstico descritivo;

c.2. Número de artigos que fazem diagnóstico gráfico com ou sem ordenação de alternativas;

c.3. Número de artigos que fazem diagnóstico numérico e/ou gráfico e numérico com alternativas pontuadas;

c.4. Número de artigos que fazem diagnóstico;

d) Disponibiliza processo para gerar ações de aperfeiçoamento?

Revista Produção Online, Florianópolis, SC, v.14, n. 3, p. 790-821, jul./set. 2014. 
d.1. Número de artigos que não se preocupam com ações de aperfeiçoamento;

d.2. Número de artigos que apresentam ações de aperfeiçoamento;

e) Número de artigos que recomendam ações de aperfeiçoamento sem processo;

e.1. Número de artigos que recomendam ações de aperfeiçoamento com processo;

e.2. Número de artigos que recomendam ações de aperfeiçoamento com processo e que hierarquizam as ações;

e.3. Número de artigos que recomendam ações de aperfeiçoamento com processo e que não hierarquizam as ações;

A Figura 17 ilustra a forma como os artigos realizam o diagnóstico da situação atual, observando que 13 artigos do portfólio bibliográfico se valem de diagnósticos descritivos, e apenas o trabalho de David, J. S., et al. (2002), que realiza o diagnóstico numérico.

Figura 17 - Lente 6: Gestão: Diagnóstico

\section{Diagnóstico}
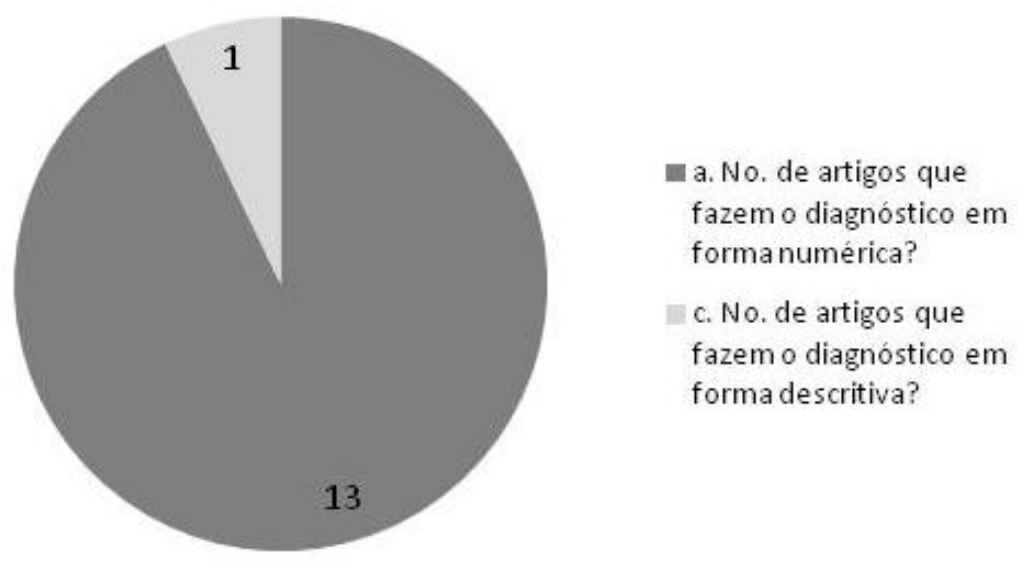

Fonte: Autores

Revista Produção Online, Florianópolis, SC, v.14, n. 3, p. 790-821, jul./set. 2014. 
Com relação ao processo para gerar ações de aperfeiçoamento, destaca-se apenas o artigo de David, J. S., et al. (2002), porém sem um processo estruturado.

\section{CONCLUSÃO}

A importância da gestão do portfólio de produtos em termos empresariais, e numa visão de pesquisa acadêmica, motivou o interesse do pesquisador pelo tema. $O$ presente trabalho construiu o conhecimento inicial necessário para que o mesmo expandisse seu conhecimento sobre o estado da arte no tema para as delimitações postas e os objetivos propostos de selecionar e analisar um referencial teórico sobre gestão de portfólio de produtos sob a ótica de seus resultados para seu gestor.

O estudo evidenciou assim 14 artigos, que compuseram o portfólio de artigos com referencial teórico para o tema Gestão de Portfólio de Produtos. Estes artigos passaram a ser considerados como os representantes do conhecimento publicado sobre o tema para as delimitações postas pelo pesquisador.

Análise bibliométrica dos artigos selecionados constatou-se: as palavras-chave, periódicos e autores de maior relevância, sobre o tema em estudo.

Verificando as palavras-chaves mais utilizadas nos artigos do portfólio bibliográfico, destacam-se:

i. Product Portfolio

ii. Portfolio Management

iii. Customer satisfaction

iv. Marketing strategy

v. Mass customization

vi. Project Management

Com relação aos periódicos do portfólio bibliográfico que mais se destacam quanto a publicações sobre o tema estão:

i. Management Science

ii. R\&D Management

Quanto à análise de autores, o processo de análise das referências bibliográficas evidenciou as contribuições de:

Revista Produção Online, Florianópolis, SC, v.14, n. 3, p. 790-821, jul./set. 2014. 


\section{i. Robert Cooper}

ii. Elko Kleinschmidt

iii. Scott Edgett

iv. Jianxin Jiao

Partindo para a análise sistêmica, considerou-se que a maioria dos autores foca o processo de "Gestão de Portfólio de Produtos" em alternativas deixando de lado os objetivos que os contextos analisados se propõem monitorarem. Poucos autores reconhecem o ambiente físico do contexto como único, e nenhum reconhecem os limites de conhecimento do decisor a ponto de manifestar preocupação em interagir para esclarecer as consequências (critérios) que o mesmo deseja monitorar e aperfeiçoar. A maioria dos artigos analisados utiliza critérios externos ao contexto, e alguns se utilizam ainda de critérios e operacionalização da avaliação sem a participação dos decisores. Com relação à mensuração, pela facilidade na aplicação a maioria dos estudos se vale de escalas ordinais, tipo Likert, a qual se evidencia neste trabalho as limitações destas escalas quanto às propriedades de sua operacionalização.

Através da análise sistêmica evidenciou-se ainda a baixa utilização do processo de integração dos critérios avaliados. Quase a totalidade dos artigos do portfólio bibliográfico se vale de diagnósticos descritivos, e apenas um realiza o diagnóstico numérico. Nenhum dos estudos possuía ainda um processo estruturado para gerar ações de aperfeiçoamento.

Os autores da pesquisa reiteram que este estudo não tenta construir um referencial teórico genérico, mas sim um portfólio bibliográfico singular ao tema e ao pesquisador, conforme sua percepção e delimitações. Pretende-se, desta forma, contribuir para que estudos sobre o contexto em pauta sejam baseados em um processo estruturado para a seleção e evidenciação dos artigos, autores e periódicos mais relevantes na área, e que suportarão os trabalhos acadêmicos e científicos futuros.

Uma limitação a ser explicitada na pesquisa, e evidenciada em alguns pontos desse texto, está na delimitação do campo amostral pelos artigos indexados pelas Revista Produção Online, Florianópolis, SC, v.14, n. 3, p. 790-821, jul./set. 2014. 
bases de dados utilizadas, e disponibilizados no seu formato integral pelo sistema CAPES de periódicos em Janeiro de 2011.

No que tange a dificuldade na execução deste trabalho, observou-se uma diversidade muito grande nas ferramentas de pesquisa e no processo de importação dos resultados em um software de gerenciamento de referências, disponíveis nos motores de busca nas bases de dados disponíveis na Internet.

\section{REFERÊNCIAS}

AGARD, B.; A. KUSIAK. Data-mining-based methodology for the design of product families. International Journal of Production Research, v. 42, n. 15, p. 2955-2969, 2004. http://dx.doi.org/10.1080/00207540410001691929

AFONSO, M. H. F. et al. Como construir conhecimento sobre o tema de pesquisa? Aplicação do processo Proknow-C na busca de literatura sobre avaliação do desenvolvimento sustentável. RGSA: Revista de Gestão Social e Ambiental, v. 5, p. 47-62, 2012. http://dx.doi.org/10.5773/rgsa.v5i2.424

AZEVEDO, R. C. et al. Avaliação de desempenho do processo de orçamento: estudo de caso em uma obra de construção civil. Ambiente Construído, v.11, n.1, p. 85-104. 2011. http://dx.doi.org/10.1590/S1678-86212011000100007

BACK, F.T.E.E. et al. Processo para construir o conhecimento inicial de pesquisa ilustrado ao tema gestão de recursos humanos. Pesquisa \& Desenvolvimento Engenharia de Produção, v. 10, p. 81-100, 2012.

BORTOLUZZI, S. C. et al. A Avaliação de desempenho em redes de pequenas e médias empresas: estado da arte para as delimitações postas pelo pesquisador. $\mathbf{R}$. eletr. estrat. neg., v. 4, n. 2, p. 202-222, 2011.

BROWN, S. L. \& EISENHARDT, K. M. Competing on the edge: Strategy as structured chaos: Harvard Business Press. 1998.

BRUNA JUNIOR, E. D. et al. Seleção e análise de um portfólio de artigos sobre avaliação de desempenho na cadeia de suprimentos. GEPROS. Gestão da Produção, Operações e Sistemas (Online), v. 1, p. 113-125, 2012.

CHAVES, L.C. et al. Mapeamento do tema Gestão do Apoio à Decisão quando analisado sob a ótica de seus resultados. S \& G. Sistemas \& Gestão, v. 7, p. 336-348, 2012a. http://dx.doi.org/10.7177/sg.2012.v7.n3.a4 
CHAVES, L.C. et al. Balanced Scorecard Na Gestão Universitária: Análise Bibliométrica Entre 2001-2011. Revista da Faculdade de Administração e Economia - ReFAE, v. 4, p. 47-68, 2012b.

COOPER, R. et al. Portfolio management for new product development: results of an industry practices study. R\&D Management, v. 31, n. 4, p. 361-380, 2001. http://dx.doi.org/10.1111/1467-9310.00225

DAVID, J. S. et al. The Performance Effects of Congruence Between Product Competitive Strategies and Purchasing Management Design. Management Science, v. 48, n. 7, p. 866-885, 2002. http://dx.doi.org/10.1287/mnsc.48.7.866.2819 DELLA BRUNA JUNIOR, E. et al. Seleção e análise de um portfólio de artigos sobre avaliação de desempenho na cadeia de suprimentos. GEPROS. Gestão da Produção, Operações e Sistemas, v. 7, n.1, p. 113-125, 2002.

ENSSLIN, L. et al. ProKnow-C, Knowledge Development Process-Constructivist. Processo técnico com patente de registro pendente junto ao INPI. Brasil, 2010a.

ENSSLIN, L. et al. Avaliação do Desempenho de Empresas Terceirizadas com o Uso da Metodologia Multicritério de Apoio à Decisão- Construtivista. Revista Pesquisa Operacional, v. 30, n. 1, p. 125-152, 2010.

ENSSLIN, L. et al. MCDA: a constructivist approach to the management of human resources at a governmental agency. International Transactions in Operational Research, v.7, p. 79-100, 2000. http://dx.doi.org/10.1111/j.14753995.2000.tb00186.x

ENSSLIN, L. et al. Um Estudo Sobre Segurança em Estádios de Futebol Baseado na Análise da Literatura Internacional; Perspectivas em Ciências da Informação; v.17, n. 2, p. 71-91, 2012. http://dx.doi.org/10.1590/S1413-99362012000200006

ENSSLIN, L. e VIANNA, W. B. O design na pesquisa quali-quantitativa em engenharia de produção-questões epistemológicas. Revista Produção Online, v. 8, n. 1, 2008.

ERNST, $\mathrm{H}$. Success factors of new product development: a review of the empirical literature. International Journal of Management Reviews, v. 4, n. 1, p. 1-40, 2002. http://dx.doi.org/10.1111/1468-2370.00075

FONSECA, F. E. A. e ROZENFELD, H. Medição de desempenho para a gestão do ciclo de vida de produtos: uma revisão sistemática da literatura. Revista Produção Online, v. 12, 2012.

GIL, A. C. Como elaborar projetos de pesquisa. São Paulo, v.4. 2002.

GOOGLE SCHOLAR. Disponível em: http://scholar.google.com.br/ (Acessado em Janeiro, 2011).

Revista Produção Online, Florianópolis, SC, v.14, n. 3, p. 790-821, jul./set. 2014. 
HART, S. et al. Industrial Companies Evaluation Criteria in New Product Development Gates. Journal of Product Innovation Management, v. 20, n. 1, p. 22-36, 2003. http://dx.doi.org/10.1111/1540-5885.201003

IUDICIBUS, S. Teoria da contabilidade. São Paulo, SP: Atlas, 2004.

JIAO, J.; TSENG, M. M. Customizability analysis in design for mass customization. Computer-Aided Design, v. 36, n. 8, p. 745-757, 2004. http://dx.doi.org/10.1016/j.cad.2003.09.012

JIAO, J.; ZHANG, Y. Product portfolio identification based on association rule mining. Computer-Aided Design, v. 37, n. 2, p. 149-172, 2005. http://dx.doi.org/10.1016/j.cad.2004.05.006

KRISHNAN, V.; ULRICH, K. T. Product development decisions: a review of the literature. Management Science, p. 1-21, 2001. http://dx.doi.org/10.1287/mnsc.47.1.1.10668

LACERDA, R. T. O. et al. Uma Análise bibliométrica da literatura sobre estratégia e avaliação de desempenho. Gestão \& Produção, v.19, n.1, 2012.

http://dx.doi.org/10.1590/S0104-530X2012000100005

LACERDA, R. T. O. et al. Contribuições à Gestão Estratégica de Organizações quando Analisados na Visão de seu Desempenho. GESTÃO. Org-Revista Eletrônica Gestão Organizacional, v.2, n.9, 2011.

MARAFON, A. D. ; et al. Revisão sistêmica da literatura sobre avaliação de desempenho na gestão de P\&D. Revista Gestão Industrial, v. 8, p. 1-43, 2012. http://dx.doi.org/10.3895/S1808-04482012000300001

MINARRO-VISERAS, E. et al. Key success factors when implementing strategic manufacturing initiatives. International Journal of Operations \& Production Management, v. 25, n. 2, p. 151-179, 2005. http://dx.doi.org/10.1108/01443570510577010

MORGAN, N. A.; REGO, L. L. Brand portfolio strategy and firm performance. Journal of Marketing, v. 73, n. 1, p. 59-74, 2009. http://dx.doi.org/10.1509/jmkg.73.1.59

PETRI, S. M. Modelo para apoiar a avaliação das abordagens de gestão de desempenho e sugerir aperfeiçoamentos: sob a ótica construtivista. PPGEP - UFSC, Florianópolis, SC, 2005. 
RAMDAS, K. et al. Managing Variety for Assembled Products: Modeling Component Systems Sharing. MSOM, v. 5, n. 2, p. 142-156, 2003.

http://dx.doi.org/10.1287/msom.5.2.142.16073

ROSA, F. S. et al. Gestão da Evidenciação Ambiental: Um estudo sobre as Potencialidade e Oportunidade do Tema. Engenharia Sanitária e Ambiental, v.16, p.157 - 166, 2011. http://dx.doi.org/10.1590/S1413-41522011000200009

ROSA, F. S. et al. MANAGEMENT ENVIRNONMENTAL DISCLOSURE: A CONSTRUTIVIST CASE. Management Decision, 2012. http://dx.doi.org/10.1108/00251741211238364

ROY, B. Decision science or decision-aid science? European Journal of Operational Research, v. 66, p. 184-203, 1993. http://dx.doi.org/10.1016/0377-2217(93)90312-B

SHENHAR, A. J. Strategic Project Leadership® Toward a strategic approach to project management. R\&D Management, v. 34, n. 5, p. 569-578, 2004.

http://dx.doi.org/10.1111/j.1467-9310.2004.00363.x

SHEU, C. et al. Integrating $A B C$ and TOC for better manufacturing decision making. Integrated Manufacturing Systems, v.14, p. 433-441, 2003.

http://dx.doi.org/10.1108/09576060310477834

SKINNER, W. The productivity paradox. Management Review, v.75, p. 41-45, 1986.

STEWART, T. R. Improving reliability of judgmental forecasts.. Principles of forecasting: a handbook for researchers and practitioners. Kluwer Academic Publishers, p. 81106, 2001.

TASCA, J. et al. An approach for selecting a theoretical framework for the evaluation of training programs. Journal of European Industrial Training, v.34, p. 631-655, 2010. http://dx.doi.org/10.1108/03090591011070761

TSENG, M. M.; JIAO, J. A Pragmatic Approach to Product Costing Based on Standard Time Estimation, International Journal of Operations \& Production Management, v. 19, n. 7, p. 738-754, 1999. http://dx.doi.org/10.1108/01443579910271692

TATIKONDA, M. V.; MONTOYA-WEISS, M. M. Integrating Operations and Marketing Perspectives of Product Innovation: The Influence of Organizational Process Factors and Capabilities on Development Performance. Management Science, v. 47, n. 1, p. 151-172, 2001. http://dx.doi.org/10.1287/mnsc.47.1.151.10669

THE THOMSON, C. EndNote. X2 ed., The Thomson Corporation, 2008.

VEGINI, D. et al. Modelo de avaliação de desempenho de fogões com foco em ergonomia, utilizando o método MCDA-C. Revista Produção Online, v. 12, n. 2, 2012.

Revista Produção Online, Florianópolis, SC, v.14, n. 3, p. 790-821, jul./set. 2014. 
YU, L.; WANG, L. Product portfolio identification with data mining based on multiobjective GA. Journal of Intelligent Manufacturing, p. 1-14, 2010.

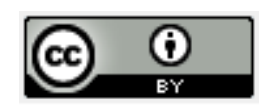

Artigo recebido em 15/07/2011 e aceito para publicação em 12/11/2012

DOI: http://dx.doi.org/ 10.14488/1676-1901.v14i3.1050

Revista Produção Online, Florianópolis, SC, v.14, n. 3, p. 790-821, jul./set. 2014. 